\title{
Assessment of the orthodontic knowledge demonstrated by dental school undergraduates: recognizing the key features of Angle Class II, Division 1 malocclusion
}

\author{
Cristiane Canavarro*, José Augusto Mendes Miguel**, Cátia Cardoso Abdo Quintão**, Myrna de Faria

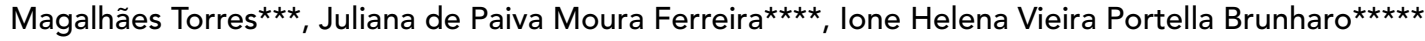

\begin{abstract}
Objective: To investigate the ability of undergraduate students in diagnosing Angle Class II malocclusion and evaluate the clinical approach of these students toward a patient displaying this condition. Methods: The sample consisted of 138 students attending the last semester of 10 dental schools in the State of Rio de Janeiro/Brazil assessed by questionnaires with closed questions. They were presented with photographs and dental casts of a patient in the mixed dentition, with Angle Class II malocclusion, increased overjet and overbite, deviated dental midlines and anterior diastemas in the upper arch. Results: It was found that students easily identified increased overjet (92\% of students), followed by the presence of diastemas (89\%), midline deviation (84.7\%) and increased overbite (77.3\%). Conversely, approximately half the sample ( $\mathrm{n}=70$ or $51 \%$ of the students) were able to identify bilateral Angle Class II malocclusion. Nearly all agreed on the need for treatment and that it should be provided by a specialist ( $\mathrm{n}=131$ or $95 \%$ ), but found it difficult to determine the ideal moment to start orthodontic treatment: $48.9 \%$ of the sample would begin treatment at the end of the mixed dentition, $41.7 \%$ would indicate treatment during deciduous dentition and $7.9 \%$ during permanent dentition. Conclusions: On completion of their undergraduate courses, students encounter difficulties in diagnosing Class II and even find it hard to articulate ideas about a basic treatment protocol to correct this malocclusion.
\end{abstract}

Keywords: Interceptive orthodontics. Angle Class II malocclusion. Diagnosis.

\footnotetext{
How to cite this article: Canavarro C, Miguel JAM, Quintão CCA, Torres MFM, Ferreira JPM, Brunharo IHVP. Assessment of the orthodontic knowledge demonstrated by dental school undergraduates: recogniz ing the key features of Angle Class II, Division 1 malocclusion. Dental ing the key features of Angle Class II, Divisi
Press J Orthod. 2012 Jan-Feb;17(1):52.e1-10.

* Visiting Professor in the Department of Orthodontics, State University of Rio de Janeiro (UERJ).

** Associate Professors of the Department of Orthodontics, UERJ.

*** Specialist in Functional Orthopedics by ABOM

$\star \star \star \star$ Specialist in Orthodontics, UERJ.

$\star \star \star \star \star \star$ Visiting Professor in the Department of Orthodontics, UERJ.
}

" The author reports no commercial, proprietary, or financial interest in the products or companies described in this article. 


\section{INTRODUCTION}

Diagnosing Class II malocclusion is a complex and critical task as it may occur as a result of diverse skeletal structures involved in combination with dentoalveolar problems. Furthermore, the identification of changes in the maxillomandibular sagittal and vertical components, be it in isolation or in combination, ${ }^{22}$ requires an orthodontists' abilities to choose the best therapeutic solution.

Orthodontic planning for these patients requires knowledge on the growth of facial bones $^{2,19}$ and determining the stage of skeletal maturation of the individual. Chronological age and dental eruption are often seen as important factors for determining skeletal maturation. These methods, however, are considered inaccurate since they usually do not coincide with the patient's skeletal age. ${ }^{4,6}$ The best ways to assess skeletal development is through hand and wrist $\mathrm{X}$-rays ${ }^{6,27}$ and lateral cephalometric radiographs with visualization of the cervical vertebrae. ${ }^{21}$ Pubertal growth spurt usually occurs in girls between 9 and 12 years old and boys aged 11 to 13 years. ${ }^{20}$

Thus, orthodontists can treat this malocclusion at three different development stages: (a) Pre-pubertal; (b) During pubertal growth spurt, in order to produce both dentoalveolar and skeletal changes; or (c) Adulthood, when growth has ceased. It is crucial that clinicians learn to distinguish between these stages as it has a bearing on the choice of therapy to which the patient will be subjected, when referred to an expert.

For patients with changes in maxillary development, headgears, such as the Kloehn and Thurow types, are best suited to control growth. ${ }^{16}$ Depending on facial pattern, patients experiencing growth may be subjected to different procedures. The Kloehn cervical headgear is recommended for cases of maxillary protrusion and reduced vertical dimension, producing effects such as: Distalization and extrusion of upper molars, maxillary growth restriction, increased vertical dimension, clockwise mandibular rotation and anterior inclination of the palatal plane. ${ }^{16}$ Maxillary splints or Thurow headgear, on the other hand, act on the maxilla due to an increased area of force application, thereby providing control over direction and location of the applied force, restricting the anteroinferior displacement of the maxilla and clockwise rotation of the mandible. ${ }^{24}$

For patients with Class II malocclusion due to a deficiency in anterior mandibular growth, the proposed therapies are often associated with functional appliances with the purpose of stimulating its anterior development in order to correct sagittal discrepancies between the jaws. ${ }^{30}$ These appliances may assist in treating these malocclusions by remodeling the condyle and glenoid fossa, thus interfering with facial development and growth. However, the increments to mandibular growth during the active treatment phase using these appliances and the stability of these changes are still important issues that need to be addressed. ${ }^{29}$

Therefore, the therapeutic intervention choice for Class II malocclusion correction is made from a wide range of approaches and types of treatment, resting on the orthodontist the task of carefully assessing them, insuring that it meets the patient's actual needs. ${ }^{23}$

Moreover, two orthodontic treatment protocols are recommended for Class II patients undergoing growth. The first one, known as twophase treatment, is initiated when the patient is in pre-adolescence (pre-pubertal growth spurt stage). The first phase aims to correct skeletal discrepancies and molar relationship ${ }^{25}$ and is performed using orthopedic-functional appliances or headgears. Next, during pubertal growth spurt, the second phase is engaged during which a fixed orthodontic treatment improves occlusion. The second protocol comprises a singlephase treatment in which the professional only 
initiates correction at the beginning of pubertal growth spurt, when skeletal and dental corrections can be performed simultaneously. ${ }^{9}$

In attempting to assess the efficacy of these two Class II treatment protocols, major studies were conducted with large clinical samples focusing on comparative results yielded by two-phase and one-phase orthodontic treatment. ${ }^{8,14,22,25,30}$ Overall, these studies compared three groups-two treated groups and one control group-to assess the effect of treatment and growth. The treatment groups underwent a first phase with an extraoral appliance (high pull, Kloehn or Thurow) and a functional appliance (Fränkel, Bionator or plateau retainer) followed by a second phase with fixed orthodontics. A control group, not subjected to the first phase, was treated only in one single phase with fixed orthodontics during pubertal growth spurt. These studies revealed that the treated groups exhibited significant improvement in their maxillomandibular relationship with the greatest maxillary effects being linked to the headgears, and mandibular effects linked to the functional appliances. ${ }^{8,14,22,25,30}$ When compared with the other groups at the end of treatment, the control group showed no clinical differences (PAR index). It was also observed that the total treatment time was greater in the groups that experienced the first phase.

Regarding the advantages of a two-phase treatment some authors believe that the approach would favor early growth modification, decreasing the duration and complexity of the second phase of treatment, improving patient self-esteem and decreasing the incidence of injuries in anterior teeth. Also, it would be carried out in pre-adolescence when there is adequate patient compliance and reduce the need for extractions, since there would be greater skeletal changes and consequently a reduced need for dental compensation. ${ }^{5,10,28}$ Currently, however, these benefits are the subject of much controversy. On the issue of reducing trauma frequency to the upper incisors, for example, recent research has shown that prevention can be achieved only when treatment is started excessively early, increasing orthodontic treatment time. ${ }^{15,25}$

Thus, those who advocate single-phase treatment also argue that the low growth activity that occurs before pubertal growth spurt would increase the length and cost of treatment, reducing patient compliance since there is no evidence to support the idea that results achieved through early intervention are potentially superior. ${ }^{13,22,25}$

Cost-effectiveness analysis of two-phase treatment showed that at least $90 \%$ of all growing patients could be successfully treated in onesingle phase, which should begin during the late mixed dentition, characterized by exfoliation of all deciduous teeth, with the exception of the second molars. These findings reinforce the fact that early treatment (pre-pubertal growth spurt) does not necessarily show favorable differences in the outcomes of orthodontic treatment for Class II when compared to the indication for treatment during pubertal growth spurt. ${ }^{9}$

This study aimed to assess the level of orthodontic knowledge held by undergraduate students attending the last semester of dentistry in educational institutions in the State of Rio de Janeiro. To this end, a questionnaire was applied to assess diagnostic skills, identification of the typical features of a patient presenting with Angle Class II, as well as clinical conduct and ideal moment to provide orthodontic treatment.

\section{MATERIAL AND METHODS}

The sample consisted of 138 undergraduate students randomly selected from those attending the last semester of 10 dental schools in the State of Rio de Janeiro, namely, Campos School of Dentistry, Rio de Janeiro State University, Fluminense Federal University, Rio de Janeiro 
Federal University, Gama Filho University, Estácio de Sá University, Volta Redonda University, Nova Iguaçu University, Rio Grande University and Veiga de Almeida University.

A standard data collection technique was used consisting of a questionnaire, which was attached to the case report (Figs 1 and 2). These were individually presented to all undergraduate students attending the last semester who were present on the visit day. No time limit was set to answer the questions. The material consisted of a header characterizing patients in terms of age
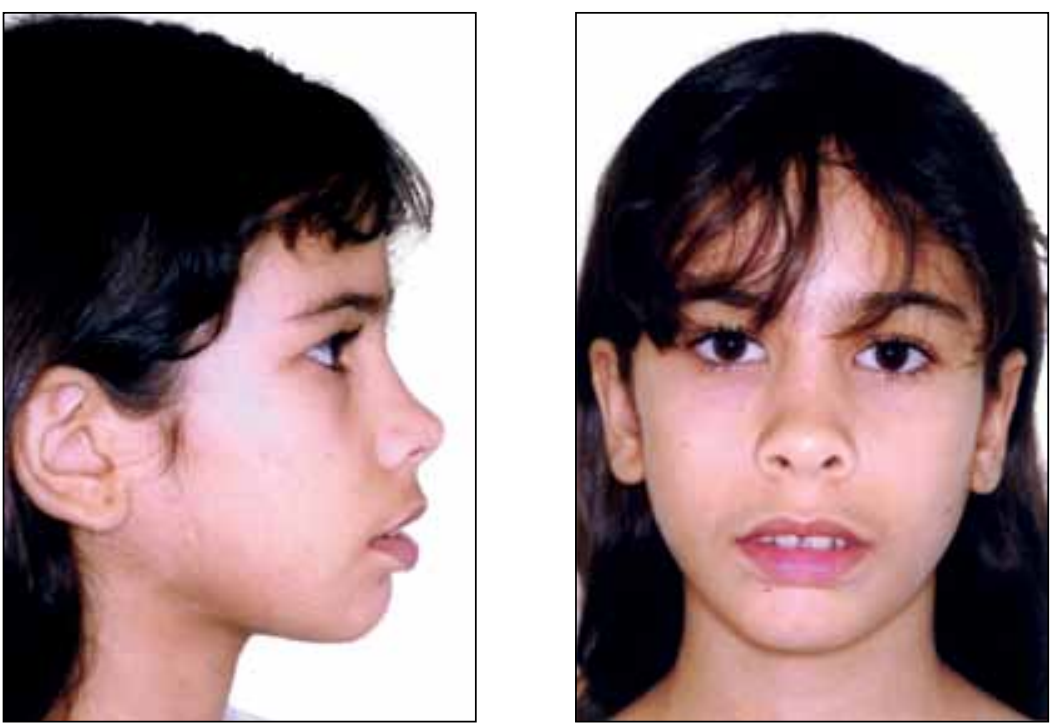

FIGURE 1 - Side profile and front photographs of the patient whose case records were presented to the students.
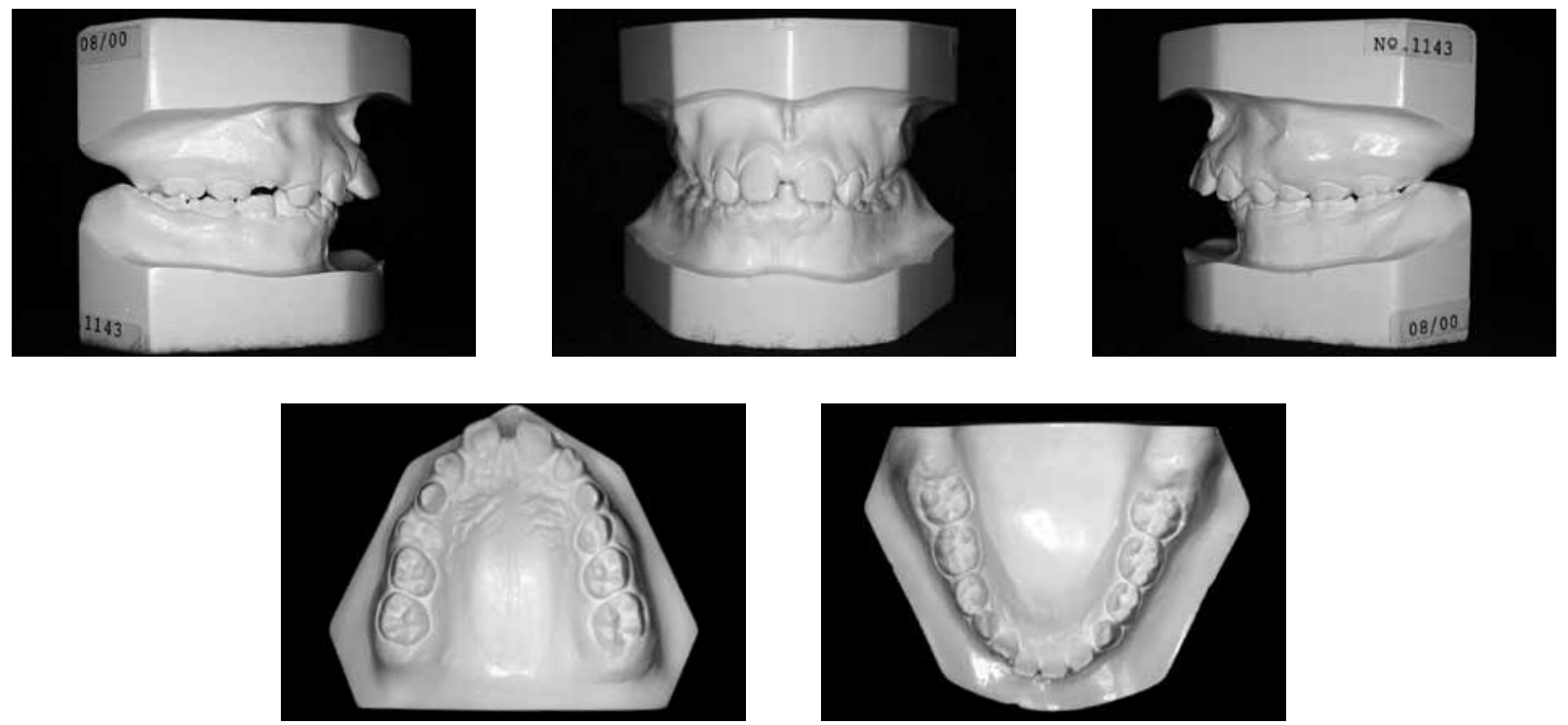

FIGURE 2 - Occlusal, front and side views of the dental casts presented to the students. 
and gender, front and profile photographs of the face and dental casts of a patient displaying Angle Class II, Division 1, with the following dental features: Increased overjet and overbite, deviated upper and lower midlines, diastemas between maxillary anterior teeth and mixed dentition. No cephalometric, panoramic or hand and wrist radiographs were provided intending to simulate a routine clinical consultation, where patients could only provide them with their clinical features. After analyzing the material, students were asked, by means of closed questions about Angle classification, existence of dental problems, the

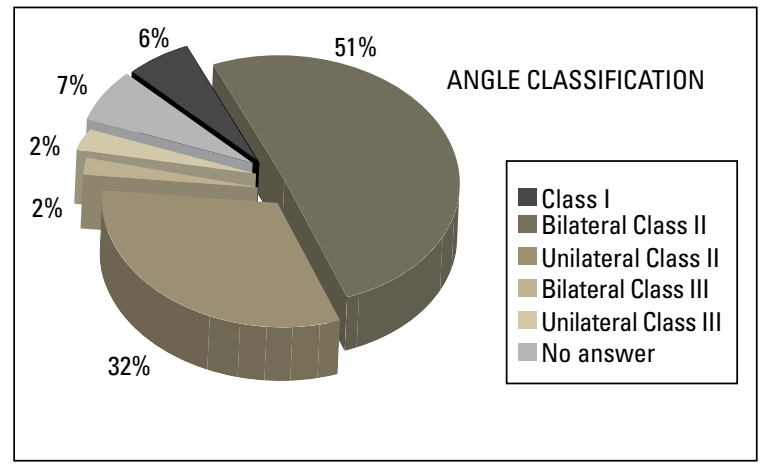

FIGURE 3 - Angle classification according to the sample of undergraduate dental students in the State of Rio de Janeiro. ideal stage for initiating treatment and the possible referral of their patient to an expert. Questionnaire responses were kept confidential to preserve student identity.

The collected data were processed and analyzed with the aid of Epilnfo software v. 6.04, and the charts were generated using Microsoft Excel 2004. Since the aim of this study was to assess the orthodontic knowledge of undergraduate students, the analysis was descriptive and comparative.

\section{RESULTS}

According to the sample configuration there was a noticeable lack of knowledge reflected in the difficulty encountered by students to accurately detect bilateral Class II, Division 1 malocclusion, since only about half of them reached a correct diagnosis $(n=70$ or $51 \%)$. Thirty-two percent $(\mathrm{n}=44)$ identified Class II subdivision, i.e., the posterior relationship was identified, however on one side only. The remaining students $(n=24$ or $17 \%$ ) failed to diagnose the problem presented to them (Fig 3).

Figure 4 illustrates the characteristics more readily recognized by respondents, with increased overjet appearing as the most easily identifiable feature (92\% of students), followed by the presence of diastemas ( $89 \%$ of students), deviated midlines ( $84.7 \%$ of students) and the least perceptible feature was increased overbite (77.3\% of students).

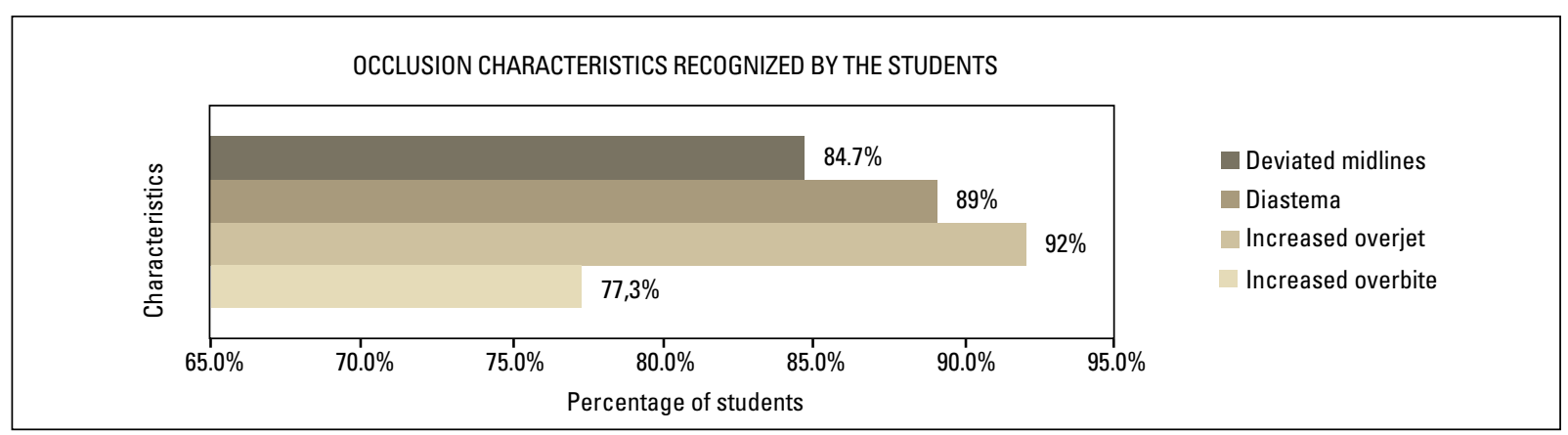

FIGURE 4 - Occlusal characteristics of the presented case as identified by a sample of undergraduate dental students in the State of Rio de Janeiro. 
Regarding the need for orthodontic treatment, the vast majority of the sample answered that there was the need to refer treatment and that it should be performed by a specialist $(\mathrm{n}=131$ or $95 \%)$, compared to only $2.1 \%(\mathrm{n}=3)$, who replied that there would be no need for treatment (Fig 5).

Figure 6 shows the results of the questionnaire applied to the students regarding the ideal stage to start orthodontic treatment considering the dental age. It was found that $48.9 \%$ of the sample indicated treatment at the end of the mixed dentition, but $41.7 \%$ opted for deciduous dentition, and $7.9 \%$ believed that permanent dentition was the right stage to begin orthodontic therapy. As shown in Figure 7, most students (54\%) were able to understand that pubertal growth spurt may be an important ally in the treatment of patients with Angle Class II malocclusion.

\section{DISCUSSION}

The intent of the questionnaire applied to undergraduate students, who had already attended the course in orthodontics, was to check whether or not some basic diagnostic concepts had been absorbed. These future dental professionals, during their clinical career, should be capable of identifying dental occlusion problems in their patients and referring them for orthodontic treatment. In Class II, where facial bone growth and development must be redirected by orthodontic therapy, it is critical that the clinical characteristics of this malocclusion, as well as the beginning of patients' skeletal maturation process, are properly identified to achieve a successful treatment.

It is notorious, however, that the curricula adopted for the orthodontics undergraduate course in dental schools across Brazil employ different teaching methods and therefore offer varied undergraduate orthodontic training. These schools should primarily focus on

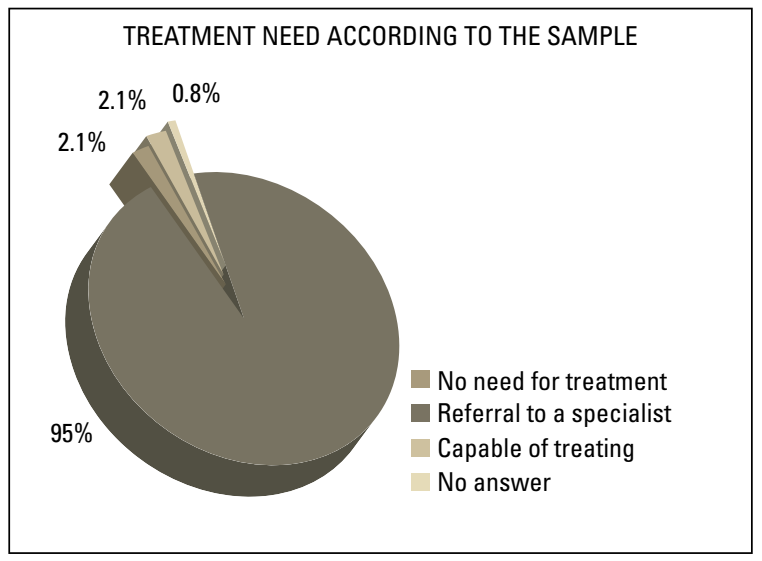

FIGURE 5 - Need for treatment of the case presented, as determined by a sample of undergraduate dental students in the State of Rio de Janeiro.

OPTIMAL STAGE FOR ORTHODONTIC TREATMENT (DENTAL AGE)

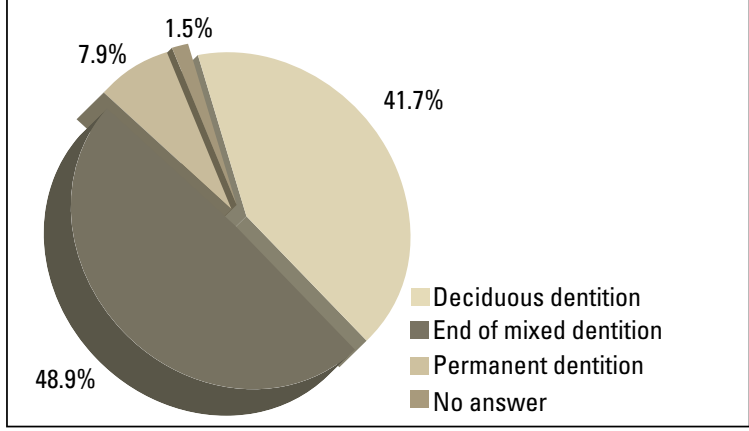

FIGURE 6 - Ideal stage for orthodontic treatment for the Class II patient taking into account dental age, as determined by a sample of undergraduate dental students in the State of Rio de Janeiro.

OPTIMAL STAGE FOR ORTHODONTIC TREATMENT (SKELETAL AGE)

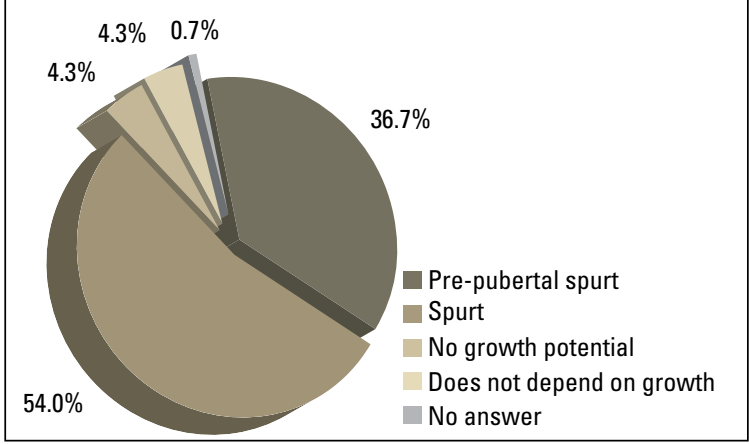

FIGURE 7 - Ideal stage for orthodontic treatment for patients with Angle Class II malocclusion taking into account skeletal age, as determined by a sample of undergraduate dental students in the State of Rio de Janeiro. 
teaching the development of normal occlusion and facial bones growth, thereby providing the foundation necessary to diagnose dentition abnormalities and deviations from the normal growth pattern.

As regards to Class II malocclusion it is important that clinicians possess an understanding of the optimal treatment time. Identifying specific dentoalveolar characteristics and, mainly, the beginning of patient's growth spurt is essential, if dentists are to refer the patient to an orthodontist at the most suitable time for treatment. Puberty signs, such as the development of physical and sexual features, are excellent indicators of this spurt. The authors deliberately refrained from providing students with cephalometric, panoramic and hand and wrist radiographs that could better identify the patient's development stage. Actually, the purpose was to simulate an initial consultation for Class II patients providing clinical information only.

In this study students were not identified, but their schools of origin were recorded in order to make comparisons and establish potential trends according to the dental schools. The undergraduate core curriculum includes lessons on the classification of malocclusions. However, after the classes, not all courses provide practical activities with dental casts, teaching how to recognize and classify malocclusions. Therefore, curricula may vary in content, and some schools only provide theoretical lessons and laboratory activities, while others also offer specific orthodontic clinics. Some schools provide this training in conjunction with the Pediatric or General Clinic, which not always are performed by the orthodontic faculty. However, surprisingly, no significant differences were found in students' responses when they were grouped by schools of origin.

Given the concern of educators and dentists in other countries, the American Association of Dental Schools, in 1980, developed a Cur- ricular Guide for Orthodontics with the aim of establishing the content of orthodontic education programs, including enough information to enable students to recognize and take action in the presence of malocclusions by differentiating cases of interceptive orthodontics from other cases which require referral to specialists. ${ }^{1}$

Deficiencies in the training of general practitioners are observed not only in diagnosing orthodontic problems but also in identifying the optimal time for treatment of various malocclusions and referral to specialists. ${ }^{12}$

Other studies used the same sample as this study (students attending the last semester of undergraduate dental courses in the Rio de Janeiro State) for Angle Class I malocclusions in the so-called "ugly duckling" stage (phase of normal occlusion development) and Angle Class III malocclusions. Both questionnaires showed that most students did not have adequate knowledge to determine the optimal stage to begin treatment. Although students were able to identify Class I malocclusion $(n=120$ or $79.6 \%)$ and deviations from normality such as the existence of diastemas $(81.7 \%)$ and excessive overbite (29.9\%), they failed to understand that in the "ugly duckling" stage these features are inherent to normal development and referred these patients to a specialist, which might lead to indicating undesirable treatment. Regarding Angle Class III malocclusion, more than half (53.3\%) took skeletal age into consideration when referring for orthodontic treatment, which is an important factor to start treatment since its orthodontic approach should be initiated prior to the pubertal growth spurt. Results from both questionnaires revealed major deficiencies in the correlation between students' identification of occlusal features and proper referral of these patients to an orthodontist. ${ }^{12,17}$

Similarly, the present study found that students had difficulty in properly identifying 
Angle Class II, Division 1 malocclusion (Fig 3), since only half of the sample subjects did so correctly. It became clear that students displayed some doubt regarding the concept of Angle Class II relationship since 32\% of them (Fig 4) identified the problem in only one side of the dental arch (unilateral Class II).

The vast majority of respondents could easily perceive the existence of dental midline deviation, presence of increased overjet, diastemas and overbite (Fig 4) since all these features are visible in the anterior region of the dental arches. They also determined that the existing problem should be treated by a specialist, since $95 \%$ of the students (Fig 5) referred the patient to an orthodontist.

In analyzing Figure 6, showing that $41.7 \%$ of the sample indicated treatment still in the deciduous dentition, one is led to the conclusion that students failed to grasp the concept of optimal treatment time for Class II. Starting orthodontic treatment at this stage would not allow the orthodontist to effectively solve the patient's main problem: Redirecting growth and development of the jaws, subjecting the patient to an excessively long treatment time. The same reasoning applies to the $7.9 \%$ who indicated treatment during permanent dentition, considering that this patient's skeletal problem could no longer be corrected, what in this case could be treated with extraction of the upper first premolars for orthodontic camouflage.

Although indications for the early treatment of Class II patients, in two phases, is highly frequent, ${ }^{3}$ treatment planning for growing patients should be performed in a more critical manner, assessing not just the outcomes, but also weighing all psychological, biological and financial costs underlying the decision. Disagreements regarding early treatment can be easily found in the literature and it is therefore important to discuss specific topics related to their validity. ${ }^{16}$ Indication of early treatment should be narrowed to cases with severe skeletal disharmony, since growth observed during growth spurt would not be sufficient to achieve optimal results, avoiding all the skeletal correction to be followed up during comprehensive orthodontic treatment.

It should be emphasized that patients with this kind of problem will be first seen by a general and/or pediatric dentist and therefore they are the ones who refer patients to an orthodontist for further explanations about the condition to the patient or their legal guardian. For that reason, these professionals should be aware of the most suitable stage to initiate treatment, which is ideally during pubertal growth spurt, when correction can be accomplished with greater effectiveness and efficiency. Despite this evidence, what actually takes place is that many experts still suggest early correction of this malocclusion. ${ }^{3,26}$ A recent systematic review published in the Cochrane Library ${ }^{11}$ further strengthens the argument that orthodontists should not perform early Class II correction, since little can be done to influence on prediction or changes in the skeletal components of the face by means of orthodontic treatment. Moreover, the best outcomes are achieved by changes in dentoalveolar components performed during growth. Therefore, the best age to start Class II treatment is between 9 to 13 years, or more specifically when the patient is experiencing the beginning of pubertal growth spurt. This emphasizes the need for professionals to detect and identify the clinical and individual features of their patients, so they can be referred to an orthodontist at the most suitable time for correcting the problem.

As regards problems related to Angle Class II malocclusion, students and future clinicians should be emphatically informed that orthodontic correction is closely linked to the patient's pubertal growth spurt stage. They should be empowered with information on indicators of skeletal maturation, which can be clinically assessed. It is important that clinicians are capable of differentiating between dental age and 
skeletal age, as studies show that there is no correspondence between these two indicators. ${ }^{6}$

In light of the results, it is suggested that more comprehensive studies be carried out in order to verify the need to alter the content of undergraduate orthodontics courses in the Brazilian State of Rio de Janeiro. Educating on diagnosis, discussion and development of treatment plans should take precedence over teaching orthodontic appliances fabrication techniques.

\section{CONCLUSIONS}

After analyzing the data obtained from the questionnaires answered by undergraduate students of dental schools in Rio de Janeiro State, Brazil, a deficiency was detected in their identification of the morphological features of
Angle Class II, Division 1 malocclusion despite the presence of striking characteristics of this malocclusion in the presented case. Additionally, the vast majority of students were unable to identify the ideal time for intervention and referral of the patient to an orthodontist.

A deficiency was therefore observed in the training of students at the end of undergraduate courses with respect to the identification of Class II malocclusion and the ideal stage for initiating orthodontic intervention.

These findings lead to a reflection about curriculum content and teaching methodology of undergraduate orthodontic courses at dental schools given their inability to qualify future clinicians to identify a malocclusion frequently found in dental practice. 


\section{REFERENCES}

1. American Association of Dental Schools. Curricular guidelines for orthodontics. J Dent Educ. 1980;44(4):223-5.

2. Björk A, Skieller V. Facial development and tooth eruption. An implant study at the age of puberty. Am J Orthod. 1972; 62(4):339-83.

3. Calheiros AA, Miguel JAM, Moura PM, Almeida MAO. Tratamento da má oclusão de Classe II de Angle em duas fases: avaliação da efetividade e eficácia por meio do índice PAR. Rev Dental Press Ortod Ortop Facial. 2008;13(1):43-53.

4. Chertkow S. Tooth mineralization as an indicator of the pubertal growth spurt. Am J Orthod. 1980;77(1):79-91.

5. Dugoni SA, Chee SO, Harnick DJ. Mixed-dentition treatment. Am J Orthod Dentofacial Orthop. 1992;101(6):501-8

6. Fishman LS. Maturational patterns and prediction during adolescence. Angle Orthod. 1987:57(3):178-93.

7. Ghafari J. Timing the early treatment of Class II, division 1 malocclusion - clinical and research considerations. Clin Orthod Res. 1998;1(2):118-29.

8. Ghafari J, Shofer FS, Jacobsson-Hunt U, Markowitz DL, Laster LL. Headgear versus function regulator in the early treatment of Class II, division 1 malocclusion: a randomized clinical trial. Am J Orthod Dentofacial Orthop. 1998;113(1):51-61.

9. Gianelly AA. One-phase versus two-phase treatment. Am J Orthod Dentofacial Orthop. 1995;108(5):556-9.

10. Graber TM. Extra-oral forces: facts and fallacies. Am J Orthod. 1955:4:409-505.

11. Harrison JE, O'Brien KD, Worthington HV. Orthodontic treatment for prominent upper front teeth in children. Aust Dent J. 2008;53(1):97-8.

12. Jacobs RM. Ten-year study of strategies for teaching clinical inference in predoctoral orthodontic education. J Dent Educ. 1979;41:477-78.

13. King GJ, McGorray SP, Wheeler TT, Dolce C, Taylor M. Comparison of peer assessment ratings (PAR) from 1-phase and 2-phase treatments protocols of Class II malocclusion. Am J Orthod Dentofacial Orthop. 2003;123(5):489-96.

14. Keeling SD, Wheeler TT, King GJ, Garvan CW, Cohen DA, Cabassa S, et al. Anteroposterior skeletal and dental changes after early Class II treatment with bionators and headgear. Am J Orthod Dentofacial Orthop. 1998;113(1):40-50.

15. Koroluk LD, Tulloch JF, Phillips C. Incisor trauma and early treatment for Class II Division 1 malocclusion. Am J Orthod Dentofacial Orthop. 2003;123(2):117-25.

16. Lima Filho RMA, Lima AL, Ruellas ACO. Estudo longitudinal das alterações no ângulo ANB em pacientes Classe II esquelética, tratados com aparelho extra-oral de Kloehn. Rev Dental Press Ortod Ortop Facial. 2003;8(2):21-9.
17. Miguel JAM, Brunharo IP, Esperão PTG. Oclusão normal na dentadura mista: reconhecimento das características oclusais por alunos de graduação. Rev Dental Press Ortod Ortop Facial. 2005;10(1):59-66

18. Miguel JAM, Canavarro C, Ferreira JPM, Brunharo IHP Almeida MAO. Diagnóstico de má oclusão de Classe III por alunos de graduação. Rev Dental Press Ortod Ortop Facial. 2008;13(6):118-27

19. Moyers RE, Riolo ML, Guire KE, Wainright RL, Bookstein FL. Differential diagnosis in Class II malocclusions. Am J Orthod. $1980 ; 78(5): 477-94$

20. Oliveira MV, Bernardes LAA. Avaliação cefalométrica das alterações verticais e ântero-posteriores em pacientes Classe II esquelética, tratados com aparelho extrabucal de tração cervical ou combinada. Rev Dental Press Ortod Ortop Facial. 2007;12(2):61-70.

21. O'Reilly MT, Yanniello GJ. Mandibular growth changes and maturation of cervical vertebrae - a longitudinal cephalometric study. Angle Orthod. 1988;58(2):179-84

22. Proffit WR, Fields H. Contemporary orthodontics. $3^{\text {rd }}$ ed. St. Louis: Mosby; 2000

23. Sassouni V. A classification of skeletal facial type. Am J Orthod Dentofacial Orthop. 1969;55(2):109-23.

24. Thurow RC. Craniomaxillary orthopedic correction with in masse dental control. Am J Orthod. 1975;68(6):601-24.

25. Tulloch JF, Phillips C, Proffit WR. Benefits of early Class II treatment: progress report of a two-phase randomized clinical trial. Am J Orthod Dentofacial Orthop. 1998; 113(1):62-72

26. Turpin DL. The long-awaited Cochrane review of 2-phase treatment. Am J Orthod Dentofacial Orthop. 2007 Oct;132(4):423-4.

27. Van der Linden PGM. Crescimento e ortopedia facial. $1^{\text {a }}$ ed. São Paulo: Quintessence; 1990

28. Vig PS, Vig KD. D. Decision analysis to optimize the outcomes for Class II Division I orthodontic treatment. Semin Orthod. 1995;1(3):139-48.

29. Voudouris JC, Kuftinec MM. Improved clinical use of Twinblock and Herbst as a result of radiating viscoelastic tissue forces on the condyle and fossa in treatment and long term retention: growth relativity. Am J Orthod Dentofacial Orthop. 2000;117(3):247-66.

30. Wheeler TT, McGorray SP, Dolce C, Taylor MG, King GJ. Effectiveness of early treatment of Class II malocclusion. Am J Orthod Dentofacial Orthop. 2002;121(1):9-17.

\section{Contact address}

Cristiane Canavarro

Av. Ataulfo de Paiva, 204/sala 510

Zip code: 22.440-033 - Rio de Janeiro/RJ, Brazil

E-mail: cristianecanavarro@gmail.com 